\title{
COMPARISON OF INSULIN RESISTANCE WITH THE SEVERITY OF METABOLIC SYNDROME
}

\author{
BHAGYASHREE N ${ }^{1 *}$, RAMASWAMY C ${ }^{2}$, RAMYA K ${ }^{1}$, GANESH M $^{1}$
}

${ }^{1}$ Department of Physiology, ACS Medical College and Hospital, Chennai, Tamil Nadu, India. ${ }^{2}$ Department of Physiology, Saveetha Medical College and Hospital, Chennai, Tamil Nadu, India. Email: bhagyashivanugraha@gmail.com

Received: 25 April 2020, Revised and Accepted: 19 June 2020

ABSTRACT

Objective: Insulin resistance (IR) means a reduced ability of insulin to stimulate glucose utilization. IR is related to cardiovascular disease (CVD) risk as the IR forms the basis for atherogenesis and acts as a major risk factor for atherosclerotic CVD.

Methods: Total of 195 participants were recruited divided into three groups based on the presence of metabolic abnormalities as control Group I (with $<3$ components of metabolic syndrome [MS]), MS group as Group II (with any 3 components of MS), and severe MS as Group III (with more than three components of MS).

Results: Results showed that fasting blood sugar (FBS) and glycated hemoglobin showed a significant difference between the groups (p<0.001), whereas fasting insulin and IR were higher in severe MS which showed statistically significant difference $(\mathrm{p}<0.001)$ in comparison with control and MS group.

Conclusion: IR is one of the principal factors for the development of MS and further threw light that the increase in the IR level proportionately increases the severity of MS.

Keywords: Cardiovascular disease, Insulin resistance, Metabolic syndrome.

(C) 2020 The Authors. Published by Innovare Academic Sciences Pvt Ltd. This is an open access article under the CC BY license (http://creativecommons. org/licenses/by/4. 0/) DOI: http://dx.doi.org/10.22159/ajpcr.2020.v13i9.38444

\section{INTRODUCTION}

IR means a reduced ability of insulin to stimulate glucose utilization [1]. In most cases, reflex compensatory hyperinsulinemia is seen in IR due to increased secretion of insulin from the beta-cells of the pancreas to maintain euglycemia [2]. IR is related to cardiovascular disease (CVD) risk as the IR forms the basis for atherogenesis and acts as a major risk factor for atherosclerotic CVD [3,4]. Increased levels of circulating free fatty acids resulted from adipose tissue form a connection between obesity and IR, and obesity forms the most important factor for insulin resistance (IR) [5,6]. Furthermore, Reaven, in 1988, proposed the concept of syndrome $\mathrm{X}$ to explain the clustering of metabolic syndrome (MS) components with IR as the common denominator [7]. MS is a constellation of diseases caused by several interconnected cardiometabolic risk factors such as hypertension, obesity, hyperglycemia, and dyslipidemia [8]. Other comorbid conditions associated with MS include vascular dysregulation, pro-inflammatory state, pro-thrombotic state, hyperuricemia, non-alcoholic fatty liver disease, erectile dysfunction in males, and polycystic ovarian syndrome in females. MS prevalence is increasing in Asia due to increased stress, less physical activity, high consumption of fast food, and changes in daily lifestyle [9].

Since obesity and diabetes are reaching epidemic proportions, understanding the role of IR and its development is gaining importance as the foremost factor of medical research. Hence, this study is designed to compare the level of IR with different degrees of MS. Homeostatic model assessment-IR (HOMA-IR) is regarded as a reliable tool to evaluate IR in individuals with or without glucose intolerance [10]. Research on the comparison of IR with the severity of MS is not yet elucidated. In this study, the HOMA-IR was used as an IR index and compared the index value with the severity of the MS. Hence, the present study was aimed to compare IR in different groups of MS based on the severity.

\section{METHODS}

The study commenced after getting approval from the Institutional Human Ethical Committee (IHEC), IHEC No. 005/12/2014/IEC/SU Saveetha University. The data collected from the participants after giving a detailed explanation about the procedure of the study and their cooperation and willingness were obtained with written informed consent. Blood sample collected after overnight fast from all patients was used to study fasting blood sugar (FBS) in $\mathrm{mg} / \mathrm{dL}$, postprandial blood sugar (PPBS; mg/dL), glycated hemoglobin $\left(\mathrm{HbA}_{1} \mathrm{C}\right)$, and $\%$ fasting insulin $(\mathrm{mU} / \mathrm{L})$ by the standard laboratory technique, and then, IR was calculated. The IR was calculated by HOMA-IR as fasting blood glucose multiplied by fasting insulin and divided by 22.5. Fasting glucose is in $\mathrm{mmol} / \mathrm{L}$ and fasting insulin is in $\mathrm{mU} / \mathrm{L}$ [11].

\section{Statistical analysis}

All the data were expressed as mean \pm standard error. The mean was analyzed by a one-way analysis of variance with multiple comparison test of Student Newman-Keuls test. Statistical analysis, as well as plotting of graphs, was carried out using Sigma Plot 13.0 (Systat Software, USA). Statistical significance was considered if $\mathrm{p}<0.05$.

\section{RESULTS}

In the present study (Table 1), the values of FBS in the different groups of the participants are as follows: Control $123.01 \mathrm{mg} / \mathrm{dl}$, MS $136.89 \mathrm{mg} / \mathrm{dl}$, and severe MS $141.10 \mathrm{mg} / \mathrm{dl}$. Observations showed significant difference ( $p=0.004)$ of FBS among the groups and in severe MS and MS, the FBS values were more in comparison with that of the control group, whereas the mean values of PPBS (control=175.87 mg/dl, MS=191.13 mg/dl, and severe MS $=193.55 \mathrm{mg} / \mathrm{dl}$ ) recorded from the subjects did not show a significant difference $(\mathrm{p}=0.064)$ among themselves. However, the mean values of $\mathrm{HbA}_{1} \mathrm{C}$ obtained in control $4.69 \%$, in $\mathrm{MS} 5.84 \%$ and severe MS $7.69 \%$ were found to be significant $(F=146.489, p<0.001)$ among all groups. 
Table 1: Comparison of FBS, PPBS, and $\mathrm{HbA}_{1} \mathrm{C}$ in control, MS, and severe MS

\begin{tabular}{|c|c|c|c|c|c|}
\hline \multirow[t]{2}{*}{ Parameters } & \multirow[t]{2}{*}{ Control Group I } & \multirow[t]{2}{*}{ MS Group II } & \multirow[t]{2}{*}{ Severe MS Group III } & \multicolumn{2}{|c|}{ Statistical information } \\
\hline & & & & F-value & p-value \\
\hline $\mathrm{FBS}(\mathrm{mg} / \mathrm{dl})$ & $123.0 \pm 3.8$ & $136.8 \pm 4.6$ & $141.1 \pm 3.3$ & $F=5.701$ & $\mathrm{p}=0.004^{*}$ \\
\hline $\mathrm{HbA}_{1} \mathrm{C}(\%)$ & $4.6 \pm 0.1$ & $5.8 \pm 0.1$ & $7.6 \pm 0.1$ & $F=146.48$ & $\mathrm{p}<0.001^{*}$ \\
\hline
\end{tabular}

Values expressed as mean \pm SE. ( $\mathrm{n}=195,65$ in each group), *Significant. FBS: fasting blood sugar. HbA C: Glycated hemoglobin, SE: Standard error

The result of the fasting insulin level and IR of the present study is presented in Fig. 1. It showed that the mean value of fasting insulin of the groups was $12.4 \mathrm{mU} / \mathrm{L}$ in control, $13.0 \mathrm{mU} / \mathrm{L}$ in MS, and $16.1 \mathrm{mU} / \mathrm{L}$ in severe MS group. Observations indicated that fasting insulin values of the different groups were significantly varied $(\mathrm{F}=7.768, \mathrm{p}<0.001)$. Fasting insulin level was more in severe MS group in comparison with that of control and MS groups. However, there was no significant difference observed in the fasting insulin level between control and MS group. Furthermore, the insulin resistance value was higher in severe MS group (5.4), which showed statistically significant difference when compared with that of control and MS group $(\mathrm{F}=10.574, \mathrm{p}<0.001)$.

\section{DISCUSSION}

In the present study, FBS, PPBS, $\mathrm{HbA}_{1} \mathrm{C}$, fasting insulin, and IR were recorded in all participants. These parameters were compared between the groups divided based on the severity of the MS as control, MS, and severe MS groups. The result of the present study (Table 1) showed that there was a significant difference in FBS and $\mathrm{HbA}_{1} \mathrm{C}$ values in severe MS when compared with that of MS and control group which was in agreement with the reports published recently $[9,12]$. Similarly, the present study result also showed that the value of fasting insulin and IR were higher in severe MS group, which was statistically significant when compared with that of control and MS groups. These results of the present study are in concordance with the work that showed a significant difference in fasting insulin and IR in the MS group when compared with that of non-MS group [12].

Elevated levels of fasting glucose are an important MS component, but neither impaired fasting glucose (IFG) nor diabetes is an absolute criterion. IR is the obvious factor in the genesis of IFG, impaired glucose tolerance (IGT), and type 2 diabetes [13]. Insulin is a peptide hormone secreted from the islets of pancreatic beta-cells which facilitate glucose absorption in most of the tissues. In the case of IR, body cells will have reduced sensitivity to insulin and thereby having resistance to insulin activity. When the cells are not able to absorb glucose, it remains in the blood resulting in hyperglycemia and compensatory hyperinsulinemia [14]. The hyperinsulinemia is very common in IR individuals due to increased secretion of insulin from the pancreatic beta-cells to maintain euglycemia [2]. Further, IR individuals develop IFG, IGT, and type2 diabetes [13].

The principal cause for the development of IR may be due to an imbalance in lipid metabolism. It is well known that obesity reduces the insulin receptor level in tissues and thereby causes IR. The IR usually associated with obesity due to excess adipose tissues in obese individuals which release non-esterified fatty acids in excess that could lead to IR [15]. During IR, free fatty acid flux is increased from the liver, which promotes the production of very-low-density lipoprotein (VLDL) from the liver. The peripheral uptake of triglycerides from VLDL is decreased because the activity of lipoprotein lipase is dependent on insulin, and it is impaired by IR. FFA itself decreases insulin sensitivity in muscle by inhibiting insulin-mediated glucose uptake [16]. The resultant hyperglycemia further increases lipid synthesis leading to hypertriglyceridemia of IR [2]. With the result, cholesterol associated with high-density lipoprotein is decreased, and simultaneous increases in low-density lipoprotein cholesterol [17]. IGT and IFG are the powerful predictors of future diabetes [18], and CVD risk increases with the progression of glucose intolerance [19]. According to a prospective

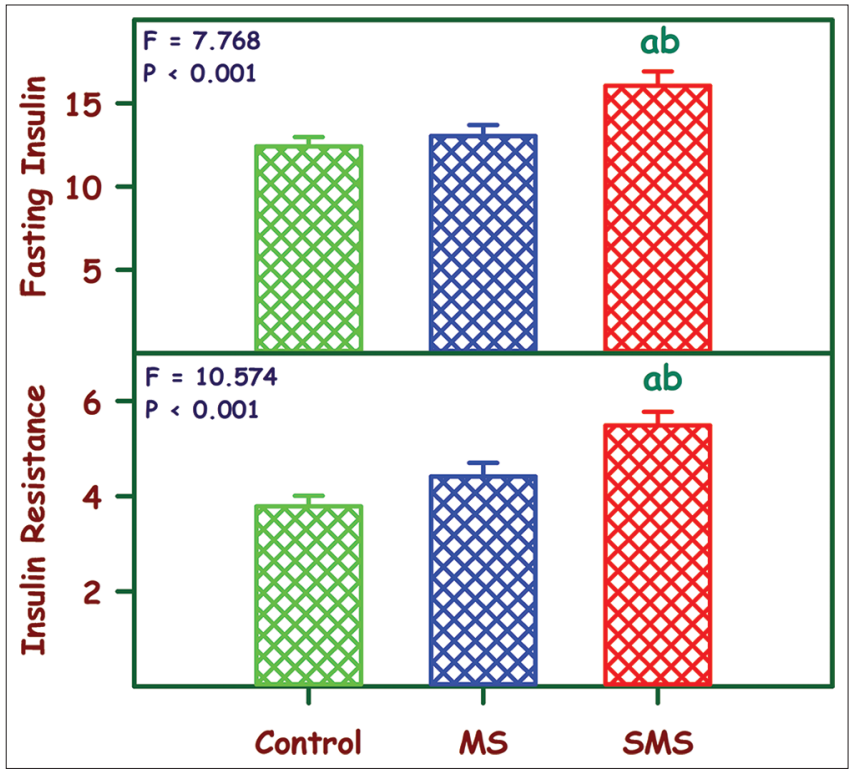

Fig. 1: The fasting insulin (FI; $\mathrm{mU} / \mathrm{L}$ ) and insulin resistance (IR) in control, MS (MS) and severe MS (SMS). aSignificantly different from control. ${ }^{b}$ Significantly different from MS

population-based study, IGT and type2 diabetes were independent predictors of advanced carotid atherosclerosis [20]. Furthermore, inflammatory markers get elevated not only due to obesity but also MS [21]. The result from the prospective study has shown that hyperglycemia and diabetes were the predictors of CVD mortality and all-cause mortality [22]

MS is a group of metabolic abnormalities that increase CVD risk. The underlying mechanism for the cause of CVD due to IR though not fully understood, the possible mechanisms include the role of IR in the development of endothelial dysfunction, inflammation, sympathetic hyperactivity and proliferation of vascular smooth muscles, and increased FFA levels and diabetes. This is supported by the available report which states that IR leads to CVD through hypertension, an increase in waist circumference, and dyslipidemia [23]. Moreover, as the insulin increases renal tubular reabsorption of sodium, both sodium and water reabsorption increased in the kidney during hyperinsulinemia, and the resultant increase in blood volume elevates BP [24].

\section{CONCLUSION}

Thus, this study supports that IR as one of the principal factors for the development of MS and further threw light that the increase in IR level proportionately increases the severity of MS.

\section{AUTHORS' CONTRIBUTIONS}

All the authors contributed to the preparation of the final manuscript.

\section{CONFLICTS OF INTEREST}

None declared. 


\section{FINANCIAL SUPPORT AND FUNDING}

Nil.

\section{REFERENCES}

1. Amanda OG, Ana Carolina JV, Mariana PZ, Antonio AB, Hessel G. Metabolic syndrome and insulin resistance in obese adolescents. Rev Paul Pediatr 2014;32:55-62.

2. Wilcox G. Insulin and insulin resistance. Review article. Clin Biochem Rev 2005;26:19-39.

3. Howard G, O'Leary DH, Zaccaro D, Haffner S, Rewers M, Hamman $\mathrm{R}$, et al. Insulin sensitivity and atherosclerosis. The insulin resistance atherosclerosis study (IRAS) investigators. Circulation 1996;93:1809-17.

4. McFarlane SI, Banerji M, Sowers JR. Insulin resistance and cardiovascular disease. J Clin Endocrinol Metab 2001;86:713-8.

5. Kahn SE, Hull RL, Utzschneider KM. Mechanisms linking obesity to insulin resistance and Type 2 diabetes. Nature 2006;444:840-6.

6. Abel ED, Karen M, O’Shea, Ramasamy R. Insulin resistance: Metabolic mechanisms and consequences in the heart. Arteioscler Thromb Vasc Biol 2012;32:2068-76.

7. O’Neil S, O'Driscoll L. Metabolic syndrome: A closer look at the growing epidemic and its associated pathologies. Obes Rev 2015;16:1-12.

8. Bhagyashree N, Ramaswamy C, Ganesh M. Importance of lipidlipoprotein ratios as a diagnostic tool in metabolic syndrome population. Natl J Physiol Pharm Pharmacol 2018;8:1668-71.

9. Maiti S, Das KL. Estimation of serum Vitamin D3 level in metabolic syndrome patients: An OPD based study in the urban area of Bhubaneswar. Int J Clin Biochem Res 2015;2:33-40.

10. Rodriguez SM, Li X, Shaffer ML, He F, Bixler EO, Alexandros NV, et al. Insulin resistance and circadian rhythm of cardiac autonomic modulation. Cardiovasc Diabetol 2010;9:85.

11. Moreira GC, Cipullo JP, Ciorlia LA, Cesarino CB, Martin JF. Prevalence of metabolic syndrome. Association with risk factors and cardiovascular complications in an urban population. PLoS One 2014;9:1-10.

12. Roopa AN, Reddy KS, Chandrashekara P, Umabai KR, Madhuvana HS. Study of microalbuminuria and insulin resistance in patients with essential hypertension and metabolic syndrome and its relationship to target organ damage. J Med Sci Health 2015;1:5-9.

13. Grundy SM, Brewer HB Jr., Cleeman JI, Smith SC Jr., Lenfant C; American Heart Association; National Heart, Lung and Blood Institute. Definition of metabolic syndrome: Report of the national heart, lung and blood institute/American heart association conference on scientific issues related to definition. Circulation 2004;109:433-8.

14. International Diabetes Federation. The IDF Consensus Worldwide Definition of the Metabolic Syndrome. Brussels: International Diabetes Federation; 2006. p. 1-16.

15. Thaman RG, Arora GP. Metabolic syndrome: Definition and pathophysiology the discussion goes on! Review article. J Phys Pharm Adv 2013;3:48-56.

16. Kassi E, Panagiota P, Gregory K, George C. Metabolic syndrome: Definitions and controversies. BMC Med 2011;9:1-13.

17. Reaven GM. Role of insulin resistance in human disease. Diabetes 1988;37:1595-607.

18. Gabir MM, Hanson RL, Dabelea D, Imperatore G, Roumain J, Bennett PH, et al. The 1997 American diabetes association and 1999 world health organization criteria for hyperglycemia in the diagnosis and prediction of diabetes. Diabetes Care 2000;23:1108-12.

19. Rader DJ. Effect of insulin resistance, dyslipidemia and intra abdominal adiposity on the development of cardiovascular disease and diabetes mellitus. Am J Med 2007;120:S12-8.

20. Bonora E, Kiechl S, Oberhollenzer F, Egger G, Bonadonna RC, Muggeo M, et al. Impaired glucose tolerance, Type II diabetes mellitus and carotid atherosclerosis: Prospective results from the Bruneck study. Diabetologia 2000;43:156-64.

21. Al-Biati HA, Sahib AS, Ismail SH. Effects of metformin and glibenclaimide combination in Iraqi obese patients with metabolic syndrome. Int J Pharm Pharm Sci 2014;6:501-3.

22. Wei M, Gaskill SP, Haffner SM, Stern MP. Effects of diabetes and level of glycemia on all cause and cardiovascular mortality. The San Antonio heart study. Diabetes Care 1998;21:1167-72.

23. Martin KR, James BM, Lisa MS, Ralph BD, Peter WW. Insulin resistance, the metabolic syndrome and incident cardiovascular events in the Framingham offspring study. Diabetes 2005;54:3252-7.

24. Montani JP, Antic V, Yang Z, Dulloo A. Pathways from obesity to hypertension: From the perspective of a vicious triangle. Int $\mathrm{J}$ Obes Relat Metab Disord 2002;26:S28-38. 